\title{
Viewer, Co-creator or Artist? Changes in the Mass Media Audience Behaviour under the Influence of Social Media and Big Data
}

\author{
Krzysztof Franek \\ Film Art Organization Department, The Polish National Film, \\ Television and Theatre School in Łódź
}

\begin{abstract}
The article deals with the issue of the influence of the evolution of contemporary mass media on the behaviour of their recipients and creators. Former passive viewers consumers of content now have an opportunity to become much more closely involved in the media message and become its active co-creators thanks to various forms of interactive interpersonal communication. The aim of the paper is to analyse the opportunities and threats resulting from these processes, with a particular emphasis on the role of humans in creating and filtering the growing collections of content available in digital mass media.
\end{abstract}

Keywords: mass media, internet, web 2.0, social media, big data, user-created content, user-generated content

\section{Introduction}

Nowadays, almost everyone owns a camera or a video camera, e.g. a high-tech SLR camera, a professional-grade camcorder, a simple digital compact or an ordinary mobile phone with the function of recording photos and videos. Photography and filming are no longer elite arts; they require neither the use of rich equipment or any difficult-to-process photoactive materials nor the acquisition of extensive knowledge and experience. Having an unprecedented opportunity to capture the world around us in such an easy and cheap manner, one may start to believe that by filling up our private digital stores or public virtual-data clouds with billions of photos and videos, we all become photographers and filmmakers. 
Figure 1. The progressive increase in the amount of digitally saved information in relation to time (numerical data in billions of gigabytes)

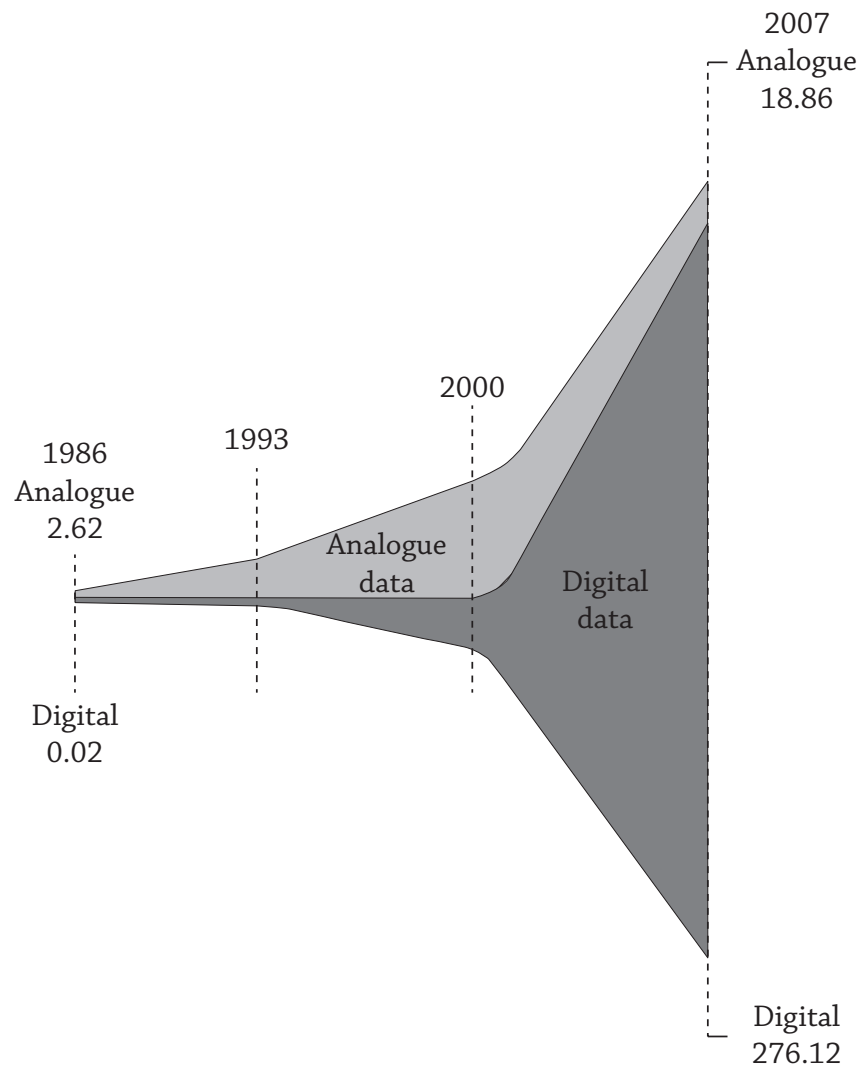

Source: Own study based on Vastag, 2011.

An average smartphone user has an opportunity to take more photos on his holiday than merely a dozen years ago any professional photographer had been able to take throughout his lifetime. In the past few years, the amount of information we save and store has been growing exponentially. According to the estimates of the leading computer hardware tycoon IBM Corporation, by the year 2000 there had been the total of around 800,000 petabytes (PB) of data saved in the world. Currently, the same amount of information is generated in just one year, and by 2020 it is bound to increase over 45 times in comparison to 2000, reaching $36 \mathrm{~m}$ PB (Zikopoulos, Eaton, deRoos, Deutsch, Lapis, 2012, p. 5). Besides, the form of data storage has also changed diametrically: analogue carriers have been replaced by digital ones. The research conducted between 1986-2007 at the University of Southern California shows that humanity has transferred from an analogue to 
digital world within mere 20 years. In 2002 digital data exceeded analogue ones for the first time. As early as in 2007, however, 94 percent of all saved information on our planet was digital (Vastag, 2011, p. 2). Figuratively speaking: over 90 percent of all information currently available in the world is digital and has been generated just within the last two years, and the amount is growing rapidly on a year-to-year basis.

The digital mode of data saving has brought many new possibilities to ordinary people, making them more eager not only to capture the reality in all its aspects, but also to create messages and to share them on a mass scale.

\section{A change of the mass communication model}

The need for creativity and communication has been at the core of human nature since the dawn of time. It can be easily satisfied at the level of individual relations, but the chances of conveying the message to the general audience by means of the traditional mass media (such as newspapers, radio, cinema or television) are still quite limited. The classic view on mass media is based on the premise that mass communication is essentially a one-way process of influencing broad audiences. All recipients, irrespective of their needs and preferences, get the same message, but are able to give none or just a very limited response (Read more: Lasswell, 1948; Hoffman, Novak, 1996; Zuber, 1999; Molęda-Zdziech, 2001).

The new electronic media break with this convention and allow to enrich a one-way transfer with a feedback (i.e. an interaction), so that a recipient is immediately able to respond to the message, without using additional communication tools. The term 'interaction' derives from the social sciences and means "a reciprocally directed action of two or more entities involved in the communication process" (Wałaszewski, 2002, p. 404). S. Rafaeli defines it as "the degree to which later messages in any sequence take into account not just messages that preceded them, but also the manner in which previous messages were reactive" (Hoffman and Novak, 1996, p. 5). For A. Sznajder, 'interactivity' is just 'any case of bilateral communication' (Sznajder, 2000, p. 68).

The traditional media are being gradually adapted to the upcoming new tech solutions. For instance, in early TV sets viewers were barely able to change channels, while in present-day ones they have a wide range of functions. And so, they can: stop, reverse or forward any broadcast, mute a dubbing speaker, add subtitles, and get updates from the electronic programme guide (EPG). What is more, advanced VoD (Video-on-Demand) distribution platforms enable their users to freely choose a programme or a film from the comprehensive database 
available anytime on demand. They even analyse the viewers' routines in order to suit programmes optimally to their viewing preferences. The process is best exemplified by the Internet - currently the most interactive of all media. It combines a multimedia message, in which the most creative human senses - sight and hearing - are engaged, with a hypertextual organization of information units, and that allows you to interact with it by means of activated links. This has a significant impact on changing the traditional mass communication process.

The possibility of interaction within and via a medium is not only playing the major role in the Internet nowadays, but also has a vast impact on the traditional media, which under its influence evolve towards integrated platforms for digital communication. What used to be television, cinema, radio, and the press, today - owing to and via the Internet - merges into one multimedia message, e.g. a newspaper text may be enriched with visual or audio materials which open up after clicking the appropriate link; or a photo may contain some interactive items which are designed for redirecting to an associated website. These contents complement and interpermeate one another on various web portals, interactive TV and radio channels, as well as in any press and music releases available online on your computer, TV, tablet or mobile phone. By interacting with them, one can create new values, messages, and contexts.

\section{The media co-created by users}

The new interactive media not only allow everyone to use content generated by others, but also enable them to convey their own messages to millions of recipients. This is a totally new approach to mass communication, as it changes its structure from the 'one-to-many' to the two-way 'many-to-many' model. Thanks to the two-way communication, an author has the opportunity not only to distribute his works, but also to engage his audience in the process of creation by consulting with them his artistic visions and ideas or asking for a review of further stages of his work. Sometimes it takes a more advanced form when people with creative aspirations set up online communities, within which they use the Internet as well as other interactive tools of digital communication for nurturing their creativities.

This social trend of co-creating and sharing new content by the web users, who exploit the networks of their close and distant contacts, is called Web 2.0. The term is recognized to have been used publicly for the first time by Robert D. Hof in the 2005 Business Week's article titled "It's A Whole New Web" (Hof, 2005, p.79). It is Tim O'Reilly though, who reportedly popularized the term most when he 
discussed the phenomenon in the extensive article "What is Web 2.0?" (O'Reilly, 2005). The Web 2.0-rooted social media, such as YouTube, Wikipedia or Facebook, compose primarily of the content created by the users of a given website (so-called UGC - User-Generated Content or UCC - User-Created Content). This approach has changed the look of the Internet in a way that was long desired by its founders. "From the very beginning, we wanted the web to be two-way, so that everyone could contribute. Unfortunately, it has failed to meet this requirement for the past decade. And at this point, let us return to the 'two-way' concept. The fact that ordinary people can write Wikipedia articles makes me extremely happy. It gives them a chance to aspire to be creators", admits Sir Tim Berners-Lee, one of the pioneers of the modern Internet (Heileman, 2008). Thus, every new media user is being equipped with innovative tools for self- expression, for reaching out to broad audiences, and for engaging them in his or her messages. Nowadays everyone, if only they want to, can become a co-creator of any medium they use (e.g. by adding or editing contents in Wikipedia, by taking part in online discussions) or they can create their own broadcasting channels (e.g. in the form of a blog, a Facebook profile or a YouTube video channel).

The former 'media guards', also called 'gatekeepers', start losing their prestige. And the notion concerns: gallery owners, museum directors, exhibition curators, art critics, newspaper chief editors, publishers, as well as heads of film studios, distribution companies, and radio and TV stations. It is they who have been restricting the access to viewers, listeners, and readers so far. Regarding the media as their own property, they have censored the contents on the most popular communication channels. Worse still, they have claimed the right to decide who, with whom, and on what terms is eligible to use these media. Even the most creative and talented artists could not show their works to a broad audience unless they descended to keep on the right side of the 'guards', trying to suit their tastes. Quite often they had to compromise or even renounce their beliefs and artistic visions.

The new interactive media, and online communities in particular, change this state of affairs. Via these media, every creator can express themselves; but most of all, they gain the opportunity to transfer their messages freely to millions of recipients, not hindered by any middlepersons or other barriers. This is a totally new approach to mass communication. The Internet is said to be one of the few media, which in most countries still quite effectively resists formal control and censorship. Due to this virtue, anybody who is just willing and capable of using the web, can freely take advantage of its potential. All you need to do is to save your message in a digital format and then - on your own, without any support from such agents as a moderator, a publisher, or an editor - make it available on one of the hundreds of thousands of websites. 


\section{The role of heavy contributors against media users}

Online communities will certainly not replace the traditional media. An average reader, viewer or listener usually has neither time nor inclination to create any content. For instance, the Polish Wikipedia - the Polish-language edition of Wikipedia, a free online encyclopaedia - is visited by over $13 \mathrm{~m}$ of unique users every month (Gemius, 2018), out of whom mere 900,000 are registered on the website. It can be edited by virtually any visitor, but in fact, there is only a small group of around 4,000 active users who do so on a regular basis (i.e. more than once within 30 days). They constitute just around 0.5 percent of the registered and 0.03 percent of the total number of visitors to the website (Wikipedia, 2018). The majority of online communities exist due to the contributions from only this small percent of their active users, who are defined as 'heavy contributors'. Representing usually less than one percent of all the Internet users, they generate over 90 percent of its content. Most web users are called 'lurkers', as they lurk (i.e. are present in an unobtrusive way) and seldom contribute, relying on what is already available to them (Nielsen, 2006).

Figure 2. The segmentation of web users based on their commitment to creating new contents

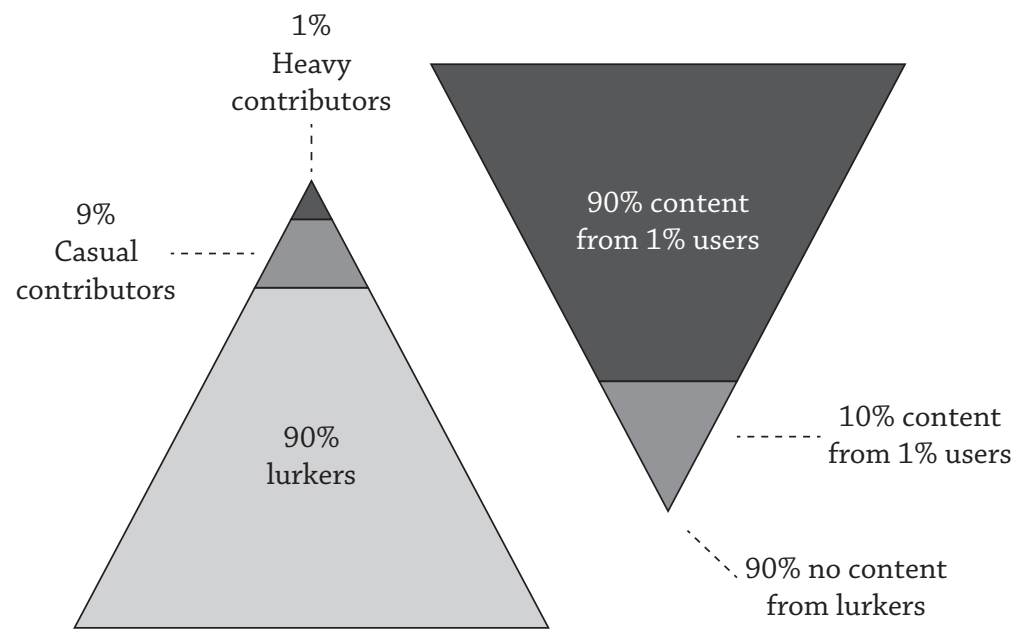

Source: Own study based on Nielsen, 2006.

Heavy contributors indeed form a meagre group, yet on the global scale, they can generate an impressive amount of new content. In 2012, the world's largest 
video-sharing website YouTube announced that its users uploaded one hour of videos every second, which translated into 60 hours of videos per minute. It is significant that two years earlier the number amounted to 35 hours, and five years later it rocketed to over 400 hours of videos per minute. Comparing this data to television, it is estimated that in just one day YouTube users publish as much video material as all the American TV stations have produced together for nine years, and if anyone desired to watch a mere two-day content of the website, it would take them a lifetime (YouTube, 2012; YouTube, 2017). The situation is similar in the case of photography. The Library of Congress houses the world's largest collection of analogue images, i.e. about $14 \mathrm{~m}$ photos and reproductions (Library of Congress, 2018). On the other hand, the members of one of the oldest photo-managing online communities Flickr, which has been operating for almost 15 years now, shared eight billion photos as early as in 2013, with a daily upload of over $3.5 \mathrm{~m}$ files (Jeffries, 2013). The next popular mobile phone application for photo-and-video sharing called Instagram, within just four years since its foundation, had collected over 20 billion of digital photos, and had been enriched by another $70 \mathrm{~m}$ a day (Instagram, 2018). As for now, however, the largest photographic archive of all time is Facebook. In 2014 its servers were revealed to store over 250 billion of photos, and the stock grew by another $350 \mathrm{~m}$ on a daily basis (Facebook, 2014, pp. 6 and 33).

\section{Figure 3. Comparison of the number of photos stored in different archives}

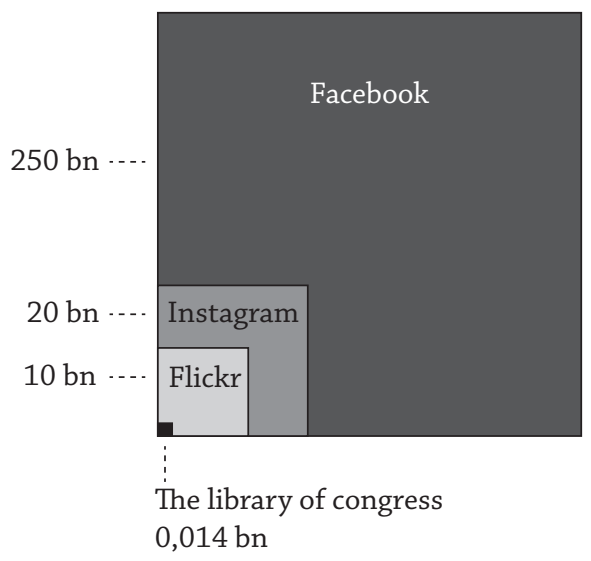

Source: Own study based on the estimates for 2014.

As you learn the data, in your first reaction you may get petrified of the number of photos and videos shared online. Yet have people not been fascinated by taking and sharing photos for up to 200 years, i.e. since 1839 when Louis 
Jacques Daguerre presented at the French Academy his invention - the first ever photography called daguerrotype? Long before the foundation of Flickr, YouTube or Facebook, had photos and videos not been one of the most popular forms of social and artistic expression? Had they not been a mode for recording our memories, experiences, thoughts? Certainly, we have never generated them so easily and on such a scale.

\section{Filtering the Big Data stocks for creative content}

Contrary to appearances, the overwhelming numbers presented above are not as much problematic as our ability to use this massive amount of content, so readily available with just a single click or tap; and the ability to distinguish what is valuable and unique from what is mediocre and trite. In the present era of global access to all information, it is becoming increasingly difficult. Until now, the decisions about what is worthy and remarkable, and what should reach a broad audience, have been made by the above-mentioned 'media guards'. But these days, their role has drastically diminished. The popularity of a given content does not depend - as much as it used to - on its circulation figures, favourable airtime, the extent of distribution, or even the advertising budget. Everybody is able to co-create messages in the web; however, it is increasingly difficult to reach any audience and draw their attention.

Let us assume that a unique photo of a beautiful woman was taken and made available to several photo-sharing sites. What are the odds that it will catch some attention and interest? Is it more valuable than billions of other photographs uploaded every day to the web? Who has replaced the former 'media guards' and who makes decisions on what is to be offered to the new media users? If, by means of Google Images, we browse the phrase "the best photo of a beautiful woman", here is a sample of what we may find...

Are the following results actually the best photos of beautiful women selected from among the hundreds of billions that can be found in the web? If we asked the same question, not to an application but to a human - an expert on photography (e.g. a gallery curator or an artist photographer) would they agree with this choice? It is worth bearing in mind that Google aspires to be such an expert, and not just in the field of photography, but in any other area associated with the keyword that its user has typed into the search box. For a vast number of web users, Google is the one and only filter which guides them through the enormous stocks of digital photos, but also of videos, books, press releases, websites, and other sites worth seeing or visiting. In Poland, Google is currently the most powerful 'guard' that 
controls the access to all web contents - and it is visited daily by over 95 percent of the Polish Internet users (Gemius, 2018). It is due to Google's advanced indexing tool called PageRank that all uploaded contents are evaluated and ranked on the list of search results. The higher-positioned ones are more likely to break into the consciousness of a broad audience, who may potentially be interested in them.

Photo 1. The search results for the phrase "the best photo of a beautiful woman" by Google

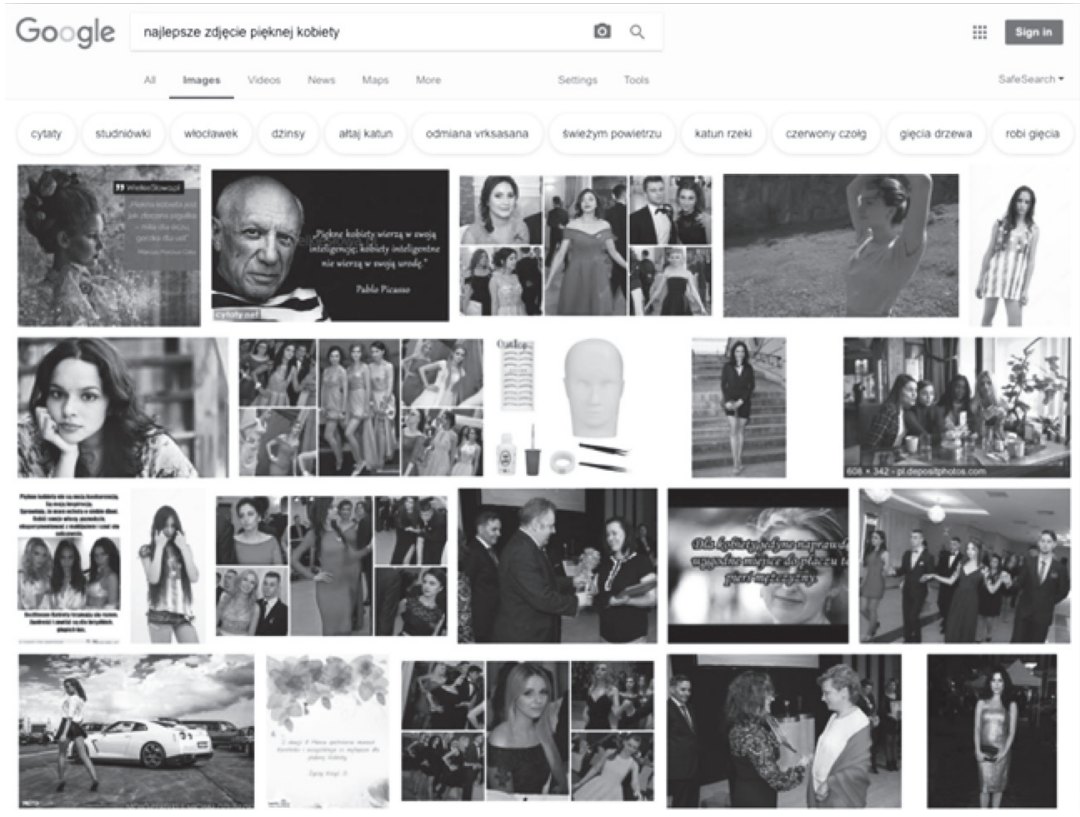

Source: Google Images, https://images.google.com/ (accessed: 19/9/2018).

Automatic scripts and filtering mechanisms are commonly used not only by Google, but also by many other social media providers that archive and share any tokens of human creativity (e.g. Facebook, Twitter, Spotify, Netflix). They become 'new guards' who aid us in finding what we are looking for, but at the same time, shape our tastes and influence the reception context. Nowadays, it is computer programmes that decide for humans what is interesting and valuable. They automatically select and prompt us what we are to watch, listen to or read. This is because the traditional analytical systems - based mainly on human skills, perceptions, and preferences - are no longer capable of dealing with this huge amount of information that needs to be processed. In the IT industry, the phenomenon is dubbed 'Big Data'. 
'Big Data' is a term used to refer to data collections that are too large or complex for traditional data-processing application software to adequately deal with. They currently pose a great challenge for all those who collect and want to use them efficiently. Many companies and organisations have been amassing data, yet they start to realise that the quantity of data does not matter as much as the ability to take advantage of them. The 'new guards', however, approach 'Big Data' in a mechanical, dehumanizing manner. One should bear in mind that web contents are only in part machine-generated, most contributions are provided by humans. Is any computer system able to properly understand all these contexts and meanings that emerge after clicking a computer mouse, typing on a computer keyboard or using a remote control? The 'Big Data' issue acquires a totally different dimension when we try to deal with creative or artistic data, such as photos, videos, TV programmes, books, pieces of music, etc. Unlike with other sets, while filtering these data one should take into account completely different factors, as the value of any creation depends on the extent to which it can influence its audience, i.e. make an impression on them, make them think, fall into their memory. Sadly enough, the role of humans in the filtration process is becoming less and less important. Being unable to process the increasing amounts of data on our own, we are compelled to entrust this task to machines. Are we witnessing the dawn of a new culture based on the tastes of artificial intelligence, which will decide for us what is a piece of art and who is an artist?

\section{Conclusion}

The new interactive media can be an interesting alternative to the products of large media concerns, which in the era of global digitisation are losing their monopoly on a broad audience. It is also a chance for young creators who are just at the start of their artistic careers. The traditional media rarely give those people an opportunity to show off their talents unless they can trade on their family name, have stunning artistic achievements as well as impressive viewing figures and sales results. In the web, to the contrary, they can quite easily reach the global audience and potentially draw their interest - this is a unique opportunity, which no representative of the old media would dare to give to them.

Although in every society, people with creative potential form a fairly small group, they can constitute a powerful source of new contents on the global scale. Certainly, among the billions of human creations which are stored daily in the memory of computer servers, there is a huge part that could be verified 
as worthless digital junk - "a fuss made by creative ambitions" - as Martin Kretschmer (2005) put it in the context of the online music market. In all that turmoil we may fear to overlook at least a few thousand valuable artistic creations, several hundred works of art or dozens of real masterpieces that are potentially generated each day. How to pick them out of the flood of so much data that pours on us from every direction?

And here automatic scripts and filters come to the rescue. The amount of data stored every second in the memory of computer servers is so large that traditional analytic systems based on human skills are not able to deal with it. The new automated 'media guards' aid us to survive in the flood of contents, at the same time however, shape our tastes and prompt us what is or is not worth our attention.

\section{References}

Gemius (2018). Wyniki badania Gemius/PBI za czerwiec 2018, Gemius S.A., 11.7.2018, Retrieved from: https://www.gemius.pl/wszystkie-artykuly-aktualnosci/ wyniki-badania-gemiuspbi-za-czerwiec-2018.html (accessed: 8/9/2018).

Heileman, J. (2008). Download: The True Story of the Internet - People Power. The Science Channel, Discovery Communications, Silver Spring, USA 2008 [film].

Hof, R.D. (2005, September 26). It's a Whole New Web. Business Week, 76-79.

Hoffman, D.L., Novak T.P. (1996). Marketing in Hypermedia Computer-Mediated Environments: Conceptual Foundations. Journal of Marketing, 60(3).

Instagram, (2018). Instagram Info Center, 2018. Retrieved from: https://instagram-press.com/blog/category/stats/ (accessed: 5.9.2018).

Jeffries, A. (2013, March 23). The man behind Flickr on making the service 'awesome again'. TheVerge. Retrievedfrom:http://www.theverge.com/2013/3/20/4121574/ flickr-chief-markus-spiering-talks-photos-and-marissa-mayer (accessed: 5.9.2018).

Kretschmer, M. (2005). Artists' earnings and copyright: A review of British and German music industry data in the context of digital technologies. First Monday, 10(1). Retrieved from: http://firstmonday.org/ojs/index.php/fm/article/ view/1462/1377 (accessed: 9.9.2018).

Lasswell, H.D. (1948). The Structure and Function of Communication in Society, In: L. Bryson (Ed.), The Communication of Ideas. New York: Harper and Brothers. Library of Congress (2018). Prints \& Photographs Online Catalog. Library of Congress, Washington. Retrieved from: http://www.loc.gov/pictures/about/ (accessed: 5.9.2018). 
Molęda-Zdziech, M. (2001). Socjologiczna problematyka komunikowania masowego. In: B. Jung (Ed.), Media, komunikacja, biznes elektroniczny. Warszawa: DIFIN, 16-39.

Nielsen, J. (2006, October 9). The 90-9-1 Rule for Participation Inequality in Social Media and Online Communities. Nielsen Norman Group. Retrieved from: https:// www.nngroup.com/articles/participation-inequality/ (accessed: 8.9.2018).

O’Reilly, T. (2005, September 30). What Is Web 2.0. O’Reilly Media Inc., Sebastopol, USA. Retrieved from: https://www.oreilly.com/pub/a//web2/archive/what-is-web-20. html (accessed: 7.9.2018).

Sznajder, A. (2000). Marketing Wirtualny. Kraków: Oficyna Ekonomiczna, Dom Wydawniczy ABC.

Vastag, B. (2011, February 10). Exabytes: Documenting the 'digital age' and huge growth in computing capacity. The Washington Post. Retrieved from: http://www. washingtonpost.com/wp-dyn/content/article/2011/02/10/AR2011021004916. html (accessed: 5.9.2018).

Wałaszewski, Z. (2002). Interaktywność gier komputerowych. In: M. Hopfinger (Ed.), Nowe media w komunikacji społecznej w XX w. Warszawa: Oficyna Naukowa, 404-416.

YouTube (2012, January 23). 60 hours per minute and 4 billion views a day on YouTube. YouTube Official Blog. Retrieved from: https://youtube.googleblog.com/2012/01/ holy-nyans-60-hours-per-minute-and-4.html (accessed: 5.9.2018).

YouTube (2017, August 1). An update on our commitment to fight terror content online. YouTube Official Blog. Retrieved from: https://youtube.googleblog.com/2017/08/ an-update-on-our-commitment-to-fight.html (accessed: 5.9.2018).

Zikopoulos, P.C., Eaton, Ch., deRoos, D., Deutsch, T., Lapis, G. (2012). Understanding Big Data: Analytics for Enterprise Class Hadoop and Streaming Data. McGraw-Hill, 2012.

Zuber, M. (1999). Wybrane teorie komunikowania masowego i próby ich empirycznej weryfikacji oraz Komunikowanie międzykulturowe. In: B. Dobek-Ostrowska (Ed.), Studia z teorii komunikowania masowego, Wrocław: Wydawnictwo Uniwersytetu Wrocławskiego, 10-41.

\section{Krzysztof Franek}

Assistant Professor and Dean's Plenipotentiary for Technology and Innovation at Film Art Organization Department of The Polish National Film, Television and Theatre School in Łódź, Poland (PWSFTViT). The creator of new media and an entrepreneur with over twenty years of experience. As the managing director and CEO of some Internet companies he has supervised the implementation of several hundred IT projects at the request of many domestic and international media companies. The expert of The National Centre for Research and Development, 
a member of the Working Group on National Intelligent Specializations in the area of Intelligent Creation Technologies at the Ministry of Development. The co-founder and member of the Eódź Media Cluster Council. The winner of many industry awards, including the title of the Leader of the European Year of Creativity and Innovation in Poland awarded by the European Commission. 